\title{
On emotions and salsa: some thoughts on dancing to rethink consumers
}

\author{
Paul Hewer* and Kathy Hamilton \\ Department of Marketing, Strathclyde University, Glasgow, G4 ORQ, UK
}

- Dance forms are a big business, highly marketable commoditized cultural universes, with a plethora of markets constructed around their spirit, vitality and possibilities. In this paper, we explore one particular dance form, that of Salsa, arguing that as consumer researchers we look for a more vibrant vocabulary and mindset with which to capture the experiential and transcendental nature of such social associations. We demonstrate that the metaphor of dancing is useful to revitalize our notions of consumer actions; taking them out of the grey mundane of calculative and rational action into the possibilities of emotional economies constructed around the effervescence and vitality of the social (cf. Maffesoli, 1996).

Copyright (C) 2010 John Wiley \& Sons, Ltd.

It is easy to see that we are living in a time of rapid and radical social change. It is much less easy to grasp the fact that such change will inevitably affect the nature of those disciplines that both reflect our society and help to shape it. (Hawkes cited in Hebdige, 1979)

\section{Introduction}

The metaphor of dancing as a form of liberation and re-enchantment for our everyday lives forms the basis of innumerable global advertising budgets - from Apple's 'Silhouettes' campaign for that most iconic and tribal

*Correspondence to: Dr Paul Hewer, Department of Marketing, Strathclyde University, Glasgow, G4 ORQ, UK. E-mail: paul.hewer@strath.ac.uk of objects the IPod, to the marketing of a lager, San Miguel with that most elusive of qualities, passion. A range of companies have employed the motif of dancing experiences to create an aura of vibrancy and vitality around their products. More so, cinematically and artistically dance has always offered the chance to move us seamlessly, liminally and effortlessly into a world of subversive potential, to free us from the reigns of routine. If you do not believe us, think only of what was for some controversially advertised in 2009 as the: 'Feel-good movie of the decade' - Slumdog Millionaire, which amongst the grime, poverty and deprivation can only end with a Bollywood dance routine of togetherness and sharing, written on the unsocial and alienated stage of a train platform. Think of the art of Edgar Degas, the sculpture of Rodin, the poems of W.B. Yeats. Think of MJ and his iconic moves. Think 
of songs which attempt to capture the power and significance of dancing to our sense of place and our pasts, each of us will have our own personal favourites.

A recurring motif written on the same terrain as that of Slumdog, a repetitive and blank stage for commuters across the lands, is the substance of TMobile's most recent advertising - whose current slogan of Stick together - sounds like the perfect recipe for our fragmented postmodern tribal times. Their current ad Life's for sharing captures this dynamic and vitality perfectly: a crowded railway station of anomic commuters brought into life through music and dance - caught in the moment, literally 'making music together' (Zaner, 2002) through a succession of popular musical styles down the ages, a choreographed and scripted exercise in the forms of body work.

In this paper, we explore one particular dance form, that of Salsa. The salsa scene is worthy of investigation given its exponential growth over the last 10 years from its roots in the Caribbean (mainly Puerto Rico and Cuba) and initial transfer to New York and Los Angeles to a phenomenon sweeping the world. Here we can draw attention to the continuing emergence of a gamut of Salsa Congresses, Latin Dance clubs and classes springing up across the globe in countries as diverse as the UK (Newcastle Evening Chronicle, 1998; Sunday Mirror, 1999), Singapore (The Singapore Straits Times, 2004), Ghana (Africa News, 2006), the US (Miami New Times, 2000; New York Times, 2007) and Canada (Vancouver Sun, 2005). Our aim is to explore the appeal of salsa, unpacking its urgency and vitality. In doing so, we contribute to understanding of the representation of emotions. Drawing on netnographic analysis, we highlight the role of online forum discussions in relation to the sharing of emotional responses through consumer narratives. Through these narratives, we also highlight that the body work of dance provides an important form of expression for the cultivation of emotionality within contemporary consumer culture.

\section{Let's go round again}

Studies of dancing in consumer research are strangely absent ${ }^{1}$, perhaps this can be explained by the all-too-limited language with which we talk of consumers. Consumers are first and foremost disciplined as 'buyers' for many in our field; but then what they 'buy' comes in a variety of forms, moreover, consuming itself can take a variety of guises. Consuming also speaks of the importance of spaces. This is why ads like Saatchi and Saatchi's Life's for Sharing work, their dynamic is to take a stage, like that of the all too familiar train station, what Marc Auge (1995) might refer to as a "nonplace' - spaces of loss, isolation, nexus points of disenchantment and routine - and to re-imagine their productive possibilities as spaces for transitory union through the inflection of dancing movement upon such an inhospitable terrain. To in other words, disturb, unsettle and enchant such spaces, if only fleetlingly, through what we might term choreographed exercises of emotional contagion.

The metaphor of dancing, is a much used one; many an author, be they singer, artist, creative, academic or even consumer has employed it to render the dynamics of consumer culture explicit. In this sense, we see little between the advertisements which feed off and profit from this resource, and the uses of dancing as a metaphor within academic work. Think only of Woolf (1993) who writing at the turn of the $20^{\text {th }}$ century speaks significantly of 'new forms for our new sensations', or better when she describes her own culture as a 'crowded dance'. Recollect too, Campbell $(1987$, p. 227), one of the unspoken founders of consumer culture theory, who was right to emphasize that what matters most in consumer cultures, is the spirit of modern consumerism which they contain:

The cultural logic of modernity is not merely that of rationality. . .it is also that of

\footnotetext{
${ }^{1}$ Notwithstanding the excellent and insightful work of Goulding et al. (2002, 2008), Goulding and Shankar (2004) and Wort and Pettigrew (2003), papers which we discuss more fully in our previous rendition on the 'magic' of salsa (Hamilton and Hewer, 2009).
} 
passion, and the creative dream born of longing.

And how does he attempt to render such longing? How does he attempt to give it form and substance? How does he attempt to make it sharable so that others might glimpse what he is trying to grasp? How else, but through the metaphor of a dance form:

The main source of its restless energy does not derive from science and technology alone...but from the strain between dream and reality, pleasure and utility. This is the source of the tune to which these twin cultural traditions dance their cultural tango in time, as it is of the conflicting tensions which many individuals experience in their daily lives. (Campbell, 1987, p. 227).

Other examples include Luker's (2008) reference to the salsa dancing researcher to highlight the process of discovery central to social science research along with Wilkinson and Young (1994) who use the metaphor of dance to represent the client-supplier relationship. We guess many other examples exist, encountered in our long-distant memories, but it establishes our central point which is that dancing matters because of its spirit and restless energy and the trick is to fix it sufficiently to grasp its profitability as an unfolding process of embodied interaction and social association. And if you do not believe us, recollect that it was Friedrich Nietzsche, he of Thus Spake Zarathustra, The Birth of Tragedy fame, who enthused: 'And we should consider every day lost on which we have not danced at least once. And we should call every truth false which was not accompanied by at least one laugh'.

One reason dancing matters is that dancing is borne of the night. A contradiction that the Life's for sharing ad makes explicit: dancing in the morning, dancing on a crowded platform well that's just not the ticket; but remember such an ad perhaps works best, or is better consumed in a darkened cinema with others of like-minded spirit. It was Leo Sayer who sang 'Dancing the Night Away' ${ }^{2}$ which establishes the point better. So, dancing and the night go hand in hand. Here our more significant point is that far too much consumer research is confined within the activities of the day, whether it be frequenting shops or the joys of banks; the night is literally the dark side of consumer research, where no-one fears to tread. But the night, is also as McRobbie (1993, p. 145) suggested significant due to its very 'otherness': 'Like the cinema, the dancehall or disco offers a darkened space where the dancer can retain some degree of anonymity or absorption. This in turn creates a temporary blotting-out of the self, a suspension of the real, daylight consciousness, an aura of dream-like self-reflection...the fantasy of dancing is more social, more reciprocated'. (McRobbie, 1993) analysis of the rave dance form, aptly expressed in the title of the paper 'Shut up and dance' speaks of the spaces of re-negotiation made possible through dance: 'The orgiastic frenzy of dance culture also hints at the fear of AIDS among young people. Rave dance legitimates pure physical abandon in the company of others without requiring the narrative of sex or romance. Rave favours groups and friends rather than couples or those in search of a partner'. We might think of rave then as celebrations of our own collective anomie and fragmentation. In contrast, other dance forms provide collective responses to alternative contexts, think here of Dyer's (1979, p. 22) analysis of disco dancing where he distinguishes rock and disco on the basis of what each 'hears' in the music: 'Rock's eroticism is thrusting, grinding - it is not whole body, but phallic...Disco music, on the other hand, hears the physicality in black music and its range... the willingness to play with rhythm, delaying it, jumping it, countering it rather than simply driving on and on...it

\footnotetext{
${ }^{2}$ As we discover from anthropological studies dance has always been seminal to archaic tribes to banish forms of evil. Think only of the tragic significance of the ghost dance or spirit dance to the lore and rituals of the Native Americans. Check out: http://en.wikipedia.org/wiki/ Ghost_Dance
} 
restores eroticism to the whole of the body, and for both sexes, not just confining it...it leads to the expressive, sinuous movement of disco dancing, not just that mixture of awkwardness and thrust so dismally characteristic of dancing to rock'. A comment which hints at the cultural and sexual politics of differing dance forms, or better the forms of intimacy practicized within particular dance styles.

Dyer's (1979, p. 22) article 'in defense of disco' is a classic in terms of its ability to take something which seems unworthy of analysis, but to instead explore the characteristic sensibility it instils, to demonstrate that it is in his words: 'worth thinking about'. This paper provides us with much of the conceptual language to explore salsa dancing. Like McRobbie's (1984) analysis of films like Flashdance and Fame, talk of social fantasy, changing forms of feminity and expressions of eroticism and romance abound. In this respect, perhaps what Dyer (1979, p. 23) says about disco could equally be said of salsa:

Its passion and intensity embody or create an experience that negates the dreariness of the mundane and everyday. It gives us a glimpse of what it means to live at the beight of our emotional and experiential capacities - not dragged down by the banality of organized routine life.

The body work ${ }^{3}$ of salsa appears more elaborate and conversational, more personal but at the same time more collective and social; it's spirit and restless vitality encoded in terms of a Life's for sharing aesthetic, as the emphasis is upon the connections and associations between people. This brings us nicely to contemporary contexts, the terrain from which such dancing springs, and a useful portrait of the current scene is painted by

\footnotetext{
${ }^{3}$ We might also distinguish such work from the labours of adornment, for as Saren (2007) reveals there is much work on the body as a site of consumption, but mainly this takes the form of studies on body-image (tattoos, cosmetics, clothes) rather than studies of social bodies in action and movement.
}

Willis (2000, p. Xv) in the Etbnograpic Imagination:

The old, 'off the shelf' cultural worlds no longer supply believable practices and materials. Class traditions, work, trade unions, organized religion, the family, parental role models, liberal bumanist education - these things no longer believably place and fill identity in connected and bomogenous ways. No one knows what the social maps are any more, there are no automatic belongings, so more than ever, you bave to work for, and make, your own cultural significance.

The body work of dancing thus takes on added significance, or better to make the distinction with that of signifiance - a term employed initally by Julie Kristeva, but described by Stephen Heath and cited in Hebdige's 1979, pp. 124-125) Subculture: the meaning of style as:

...a process in the course of which the 'subject' of the text, escaping (conventional logic) and engaging in other logics (of signfier, of contradiction) struggles with meaning and is deconstructed ('lost'); signifiance. . is thus precisely a work; not the work by which the (intact and exterior) subject might try to master the language...but that radical work leaving notbing intact) through which the subject explores - entering not observing - bow the language works and undoes bim or ber... ${ }^{4}$

\footnotetext{
${ }^{4}$ Hebdige's example here is the Punks' dance form, that of the 'pogo' or 'high rise leap' which '... resembled the 'anti-dancing' of the 'Leapniks'... abbreviated gestures leaping into the air, hands clenched to the sides, to head an imaginary ball - were repeated without variation in time. . the pogo made improvization redundant: the only variations were imposed by changes in the tempo of the music - fast numbers being 'interpreted' with manic abandon in the form of frantic on-the-spots, while the slower ones were pogoed with a detachment bordering on the catatonic.'
} 
Tricky stuff we admit, and semiotics, poststructuralism and postmodernism always suffered from this problem: that of making itself heard and understand through language. Perhaps best paraphrased through reference to a Sister Sledge ode: 'We're lost in music, caught in a trap, no turnin' back'. But our more serious point is that dancing brings in its gyratory wake the promise of transformation and transcendence, if not quite achieving full escape: forms of flight in a particular context and set of circumstances within our choosing. More so, as Frank (1991, p. 80) reveals dancing is communal, bringing forth particular 'forms of dyadic associatedness which transcend the individual body to that of the other'. Here we might equally turn to Maffesoli's (1996, p. 81; with a little help from Georg Simmel) account of tribalism, and his definition of such 'forms' as the 'thread of reciprocity that is woven through individuals. It is a kind of thread in which the intersection of actions, situations and affects forms a whole, hence the metaphor: dynamic in terms of weaving; static in its social fabric'. The experience of embodiment, what we term the body work essential to its expression and understanding, becomes in our minds all important for a rethinking of consumers and their practices, especially as what we glimpse through attention to dance and the performative realm is a reconsideration of the 'human body as a moving agent in time and space' (Thomas, 2003, p. 78). Dancing thus becomes that feeling of movement and (e)motion made visible, for others and ourselves to deploy as a resource for forms of individuality, forms of togetherness and community formation.

We suggest that a turn to such dance forms demands that as consumer researchers we look for a more poetic and vibrant vocabulary to capture and render such passionate and intoxicating dance experiences as strange rather than all too familiar. How to render salsa as inspectable (Geertz, 1974)? How to recapture its vitality: especially when we consider the paradox, as Willis (2005) does, that interpretation sets itself the task of 'render[ing] into language that which is formed partly as an escape from language'. Here perhaps lies the attraction of dancing, its allure and promise, a practice beyond the mundane and everyday which in part explains why it is employed as a metaphor in countless advertising campaigns. But more, for our task is that of making such an act explainable, being aware as McRobbie (1984, p. 143) suggests that: 'Dancing seems to retain at its centre a solid resistance to analysis. So deeply have we absorbed its rules and rituals'. What we try to achieve in this interpretive paper is to focus upon the narratives of salsa dancers to unpack the stories they themselves construct around this experience, so a kind of reverse etic/emic perspective where we rely upon our informants for their moments of 'unpicking', rather than our own, theorizing and interpretive capabilities (Stern, 1998). In this respect, we adhere to Brown's (Brown, 1998, p. 248) recommendation that 'next time you sit down at your desk, remember that third-person, passive-voice, unadorned modes of expression are a custom not a command, a convention not a condition, a choice not a covenant'. Enough said on theory, time for method.

\section{Emotional methodologies}

Our literature review sets up a set of important questions around the possibilities of dancing, and its resistance to analysis. What it thus brings in its tow is a view of methodology as a particular sensibility, a particular way of seeing, experiencing, documenting and understanding such all too consuming and corporeal experiences. Here a methodology is less about the basic choices we make around our analysis - who, what, when, how - rather it critically has much more to do with our position and how we theorize through the data which reveals itself to us. Here analysis is less a question of coding, less a question of sampling, less a question of reliability; instead method becomes the putting into practice of a sensibility and way of feeling, or as Willis (2005, p. 113) suggests in terms of field relations as a 'form of reflexivity, emphasizing 
the importance of maintaining a sense of the investigator's history, subjectivity and theoretical positioning as a vital resource for the understanding of, and respect for, those under study'.

The material presented in this paper was collected through a netnographic analysis of an online salsa forum (http://www.salsaforums. com). Drawing on the excellent work of Kozinets (1997, 1998, 2001, 2002) we argue that a netnographic analysis transcends the 'limits of asking' through observation of people's talk. Salsaforum attracts people from all over the world. The forum began in February 2004 and a testament to its growing popularity is the fact that there are now 20462 registered users (of which 2577 are active), who have made a total of 110955 postings since its outset. Members vary dramatically in usage; some have not made any postings and the most active user has made a total of 7728 posts, averaging 4.03 posts per day (figures correct on 1 June 2009). The forum provides an arena for members to discuss salsa music, share salsa video clips, announce events and offer reviews of salsa clubs, DVDs etc. While not representative of the salsa tribe, the discussions reveal some interesting insights on the ways that dancing matters.

\section{Findings}

From our analysis of salsa forums, it is clear that emotions are central to the salsa dance experience. Discussions are awash with members' anecdotes and narratives that convey their 'salsa good-feeling'. For some, emotional responses are complex and difficult to articulate and as a result, what we find on the forum is a turn to a poetic vocabulary as salseros seek a means of communicating their reactions and dance experiences to 'rouse passion and emotion' amongst others (Sherry and Schouten, 2002, p. 222). As will become evident, the language they employ is impassioned, ardent, beautiful and metaphorical clearly illustrating that salsa is a dance form that falls outside the limits of the rational auspices of Western societies (Thrift, 2000). Some forum members have a strong desire to share emotions and endeavour to express themselves with thoughtful and eloquent postings:

I actually find it monstrous of my inability to truly write what it is that I feel, bence, a belief that I've cheated the world from "experiencing" the very feelings within my body. That I manage to impress you more and more lets me know that I'm beading in the right direction

As a result of the powerful communication between members, the forum serves, we argue, as a rich repository of cultural meanings seeking to embody the social dramas of contemporary consumer culture (Turner, 1982). We thus explore and discuss this in relation to two core themes: emotional expression and emotional connection.

\section{Emotional expressions}

This section relates to the expression of emotion through salsa dance as bodies move in ways that have 'the power to generate so much happiness'. While the body often appears as absent in theorizing consumer culture, the sensuality of emotional states produced through salsa music allows the body to take centre stage. Emotional expression through the body appears key for salseros as forum members highlight the importance of 'the connection to the moves, that each move is not merely a movement, but an expression of an emotion be that lust, joy, sadness, excitement, or pure unadulterated fun'.

Emotions created through salsa are strong, reaching exuberance, elation and 'The 'thank God' feeling that my body and mind can take me to that beautiful place of euphoria again that comes from dancing'. In some senses the salsa dance floor has qualities of otherworldness where salseros can find temporary escape from the mundane, relief from the stresses, tensions and contradictions of 
everyday life and instead enter a more enchanting and sacred space:

Anotber thing about salsa is bow it takes you away from your current situation. Dancing away your worries. You can just release everytbing from your body, driving it into the floor when you dance and releasing it into the music around you.

I love it when everything around me seems to disappear, when there's just me, my dance partner and music. In those moments I feel so much passion, so much energy. . . I truly feel life in my veins. That's better than. . .well. . anything!

This 'passion' is indeed clear from the enthusiastic nature of forum postings as members' debate and share salsa-inspired conversations. Passion, defined by one forum member as 'the sum of your physical and emotional self-expression' is perhaps what drives dancers to increasingly embrace salsa into their lifestyle: 'a lifestyle where salsa is your world' to the extent that it 'starts to become a part of you'. Whether ignited by the music, the dancing or a particular dance partner, for many salseros passionate expression is seen as central to entertainments of the salsa experience. Indeed, one thread which generated a significant amount of discussion was devoted to this issue. Entitled 'Passion in your dance' many forum members agreed that such an emotion is more important than technical perfection:

You can be technically flawless but if you're passion for dance doesn't come through, then basically you're just a robot mechanically moving through the steps or patterns.

'Dancing without passion is but bodies in motion, for motion to become dance, passion must be present'.

Passion becomes an important ingredient then of the experience and such an emotion is enhanced by the music which is seen as a powerful and energizing force that vitalizes the body. As one participant observed, 'it touches me deeply. ...The pleasure I get from the music alone is intense'. While technical skill and mastery of the steps undoubtedly makes participants feel good, especially when learning a new move for the first time, this is not deemed to produce the best style of dance. Rather many believe that truly good dancers are those who not only listen but 'become one with' the music, 'feel' it in their 'heart and soul' and translate such emotion into movements of the body.

For some, this is closely linked to selfexpression. As one forum member commented 'it's the freedom of expression and the freedom of movement. There's something powerful about being able to hear a song and dance the way the song makes you feel and express what you hear in the music'. This style of movement requires no thought rather: 'it's as if the music literally moves them!' It is clear that the ability to dance in this way is something that requires a certain amount of salsa experience. As a dance form, there are certain basic techniques that salseros must learn and it is once these become, 'engraved into your muscle memory' that the potential for liberation occurs. Paradoxically then, 'learning the rules frees you to 'break' the rules' as the basic steps come naturally and rather than constraining movement provide the basis for what they see as a 'truer' form of freedom.

Freedom through salsa affords release from everyday bodily constraints as the dance floor offers a space where movement is not directed at instrumental or practical goals but is channelled into forms of self-expression and action centred upon pleasure and enjoyment. On the dance floor, salseros have the opportunity to play with their bodies, enacting 'the bodily lived basis of our freedom in an aesthetic form' (Fraleigh, 1995, p. 19). Such freedom creates potential for the release of aspects of the self that are often hidden to others. As one respondent commented, 'Sometimes the you on the floor can be more "you" than the person off the floor just like an artist might express the deepest part of themselves 
through their paintings but nowhere else'. Participants attempt to 'find yourself in the dancefloor' and contact with 'inner dancers', revealing in Bourdieuian terms (1992, p. 190) 'the deepest dispositions of the habitus'. In this sense, Salsa can be seen as a medium of expression through the communicative body, that is, a body in the process of creating itself (Frank, 1991).

\section{Emotional connections}

Salsa dancing not only generates individualized emotions but also the sharing of emotions through the potential to 'share this expression and interpretation'. Goulding et al.'s (2008) research acknowledged the 'empathetic bond' that exists between clubbers. Likewise, the salsa dance floor is somewhat tribal in nature, however, what differentiates salsa is the almost nostalgic emphasis on the bond between two people. As a couple dance, we are told that the best dances are those where you 'cease being two people dancing with each other, and become a couple dancing together'. This relationship, described a 'mysterious union', 'gratifying connection' and 'magical moment', can be achieved with both regular dance partners and strangers. The difficulty of putting this chemistry into words motivated participants to use various metaphors to express and understand their experiences: 'When that spark ignites it's great; it's like a story being read for the first time' and 'We're painting a story together and the dancefloor is our canvas'. Whereas bodily behaviour in public spaces is often rule-governed as individuals maintain 'territories of the self' (Goffman, 1972), in salsa dancing, that personal space can expand to include the extended body, that is, the body of the other. In this way, salsa draws our attention to the fluidity of the boundaries of the body:

You bring down your barriers, as much as the music and your personality allows, to share yourself with your partner. When there is some attraction the dance can be quite powerful. You can give yourself over to the other person connecting on a deeper level than the physical.

When I dance I love expressing the passion and the sensuality that I feel inside. But, it isn't automatic with everyone... I think some people are just not used to allowing themselves to express themselves that way... There are some hot dancers I meet and in an instance I feel they are okay with $i$, dancing that way. So, when we dance, what happens is just sheer magic. Sometimes, when I look back, I'm thinking, I can't believe I did that with him.

As the above comment suggests, salsa dancing appears to demand that participants are in touch with their inner emotions, something that not all dancers can readily achieve. It is only those who can overcome the limits of rationality who experience the 'sheer magic' that is afforded to those who release and express their 'passion and sensuality'. One explanation for this difficulty is the way in which salsa dancing may conflict with societal expectations and norms as explained by one forum member, 'society at large does not teach us how to become in tune with our feelings but rather, how to look to the outside and be lost in exoteric ideals; a material world that is only to be happy with external possessions...' Salsa appears as a way to fulfil the 'emotional hunger' (Cushman, 1990, p. 600) generated by consumer culture as inhibitions are brushed aside and salseros experience the 'loss of oneself in another' (Maffesoli, 2007) to practice a form of critical inquiry.

One particularly eloquent posting illustrates how the sharing of emotions in the dancing couple can be achieved through the mere touch of a hand, 'Make her feel every emotion deep inside a heart through those hands, with the care of a mothers grasp to her new born child. A lovers run of his figures through a sleeping-beauty's face with every care in the universe as not to wake her...'. When such a connection is achieved, salseros can be transported to another time and place and 
enjoy a transcendent experience as salsa emerges as a form of social fantasy:

I wish there were more leads out there that would open themselves to the language of bands, to the tenderness of dance, and to the bonour and magic of buman connection. I don't flirt to get a rise out of you. I flirt to find that place where there is no barrier between eyes, where there is no shame or restraint in touch on the dance floor (off the dance floor is another story. . . ) I want to forget that i'm dancing and sweating, and I want to live a timeless story with you. I want to recreate the lives of the lovers that Greek songs are written for... parted soulmates; a sailor on an endless voyage and a passionate beauty waiting in tears for him on the shore. It's so borribly romantic and painful and wonderful, and it's timeless and universal. Let's feel that again in these few minutes we have. Let's recreate centuries of lovers in this one song on this one floor...

While acknowledged as integral to everyday life, fantasy is often considered only in relation to 'the inner theatre of the mind' (Cohen and Taylor, 1992). Salsa dancing provides the opportunity for an embodied practicizing of fantasy and the dance floor becomes a space of emergence and possibility. As one forum member suggested it is a world where 'everything is effortless, no performance anxiety, no feelings of superiority or inferiority'. A number of salseros compare the emotions generated through salsa with the experience of falling in love suggesting that the 'spirit of salsa' makes 'time stand still' as dancers lose themselves in the moment. The dance floor is then a liminal space where salseros experience what Turner (1982) refers to as 'a moment in and out of time'.

Forum postings indicate that while there are undoubtedly some people who take advantage of the sensuality of salsa, generally, the dance floor is viewed as a safe environment where salseros accept and embrace the challenging of everyday codes of bodily conduct 'Because on the dance floor women don't feel as if they are going to be taken advantage of or placed into awkward and inappropriate situations'. This is not to say that boundaries are non-existent. Rather that the dancing couple becomes responsible for re-negotiating what the dance signifies and thereby reconfiguring the boundaries for appropriate behaviour.

Fantasy has a potential to open a special world of play (Belk and Costa, 1998). While for some, this may be the innocent desire to dance with a 'Prince Charming', the sensual nature of salsa and the emotional connection leads one to consider the role of sex. ${ }^{5}$ One discussion thread began with a poll entitled 'Does sex have a place in salsa?' A total of 61 members voted in this poll (41 males and 20 females). Only 5 answered that sex has no place in salsa with the remainder suggesting that sex has either some place or a big place in salsa with comments such as:

Sexual energy definitely has a place in salsa - if you can convince your partner that you bave the absolute bots for ber during a dance, then in my opinion that's a job well done It may only be an act, a ritual if you like - but there is definitely a place for this.

This suggestion of 'an act, a ritual' again draws attention to the make-believe, fantastical element of salsa. There is recognition amongst forum members that sexual energy on the dancefloor is not real. Several women share the opinion that 'dancefloor chemistry has almost nothing to do with personal compatibility'. In this way close bodily contact is seen as part of the dance and nothing more. It is a fleeting connection, illusionary yet real. Indeed one male forum member suggested that, in comparison to sex, salsa 'is a lot more lighthearted, innocent and playful. The consequences of

${ }^{5}$ In some cases, dance can be viewed through an anthropological lens as a mating ritual, raising important yet little-recognized gender issues, see Hanna (1988) for more on this. 
dancing seem a LOT NICER, INNOCENT and BETTER than sex'. Salsa is thus about 'playful flirting' with many emphasizing the importance of sensuality to avoid the dance becoming 'sterilized', 'antiseptic' or just another fitness activity.

\section{Conclusions}

This paper highlights the various ways in which the metaphor of dancing has been employed both in commercial marketing and as aid to understand and frame consumer culture. Added to this, we demonstrate throughout the findings that dance can also be thought of as metaphor for 'writing the body' (Thomas, 2003, p. 173), but also for rewriting social relations and associations in a more humane form. Drawing on the work of Wolff (1995), Thomas (2003) challenges the misleading assumption that as a non-verbal mode of communication, dancing falls outside of language's signifying process:

Because, unlike walking or swimming, dance is perceived as creative, it is seen to articulate the authentic expressions of the body. From these assumptions the conclusions are drawn that dance is or may be liberating and, a fortiori, that metaphors of dance operate automatically as critical theory. (Wolff, 1995, pp. 79-80 cited in Thomas, 2003)

Dancing in some instances appears to take the form of a critical poetics. Through the narratives of salseros as they struggle to articulate their dancing experiences, it becomes apparent that emotions are pivotal to the salsa experience. By way of implications, we believe their renditions on this experience serve only to question notions of a postemotional society (Mestrovic, 1997). According to Mestrovic (1997), society today is plagued by an 'emotional sterility' (p. 26), it is, he believes, a society where emotions are mechanized or extending Ritzer (1993), McDonalidised through what Theodore Adorno and Max
Horkheimer referred to as the Culture Industry. In this way, 'the language-as-consumergood is no longer primarily the carrier of rationally intended meanings but now carries standardized emotions as well' (Mestrovic, 1997, p. 55). Further implications stem from the argument that emotions and their exchange has always been big business. Dance forms like salsa, rave, disco etc. are highly profitable and marketable commoditized cultural forms, with a plethora of markets constructed around their vitality, spirit and possibilities. This suggests that analysis should turn to such creative industries and learn from the forms of innovation practiced therein (see also Wilkinson and Young, 1994). An imaginative industry has been constructed around profiting from our passion and desire for dancing, which offers to many a form of 'societing' (Cova and Cova, 2002), or better as De Certeau et al. (1984) prefers a logic for 'a thereupeutics for deteriorating social relations'. The desire for movement and possibility expressed through dancing may, we argue, speak of a 'lack' in Deleuzian terms. A lack of social affiliation, a lack of social communion, a lack of desire nourished through the incessant beats, urgency and possibilities of music. Here, as Butler (1993) suggests 'Bodies matter', becoming the allimportant terrain for a renegotiation of our sense of identity, our dislocations and our sense of fragmentation.

We argue that emotional expression on the forum is far from 'standardized', instead postings are touching, thoughtful, eloquent and sometimes poetic. In this way, the forum provides an important representation of the salsa experience. Through their narratives, salseros themselves engage in forms of theorizing on the forum as they debate what salsa represents. The vitality of online forum discussions speaks of how consumers deploy dance forms such as salsa as a way of resolving contradictions in consumer culture, offering a space for attempts at making sense of their own 'placelessness' (Gitlin, 2002); and offering respite and a fixing (if only temporary) from anxieties over time, organization and the 
grey economic of such things as the credit crunch. In this sense, further implications suggest that a turn to dancing necessitates a reworked palette of terms within consumer research to account for consumer actions; talk of buyers is surely past it's sell by date, as is the prominence of cognitive over aesthetic experiences (Venkatesh and Meamber, 2008). Indeed, Brown (1998, p. 76) argues that aesthetic expression is capable of 'articulating the inarticulate, speaking the unspoken'. What we require then is a form of methodological sensibility and language to reconstruct and understand such experiences; a method that prioritises the consumer's voice and a language that stems from the actual consumer experience (Stern, 1998). A turn to dance then brings in its wake terms like desire, passion, rhythm and movement; moving bodies meeting and interacting in concert, but it also bring us back to Max Weber and talk of empathy and the significance of a shift to emotional communities (1968).

That these emotions are translated into body movement on the dance floor further highlights that not all means of escape have been rationalized. Although dance forms, in our case salsa, can involve a certain amount of ritualized interaction, we have shown that central to its appeal are the qualities of practice, performance, and emotion brought into play. Such aspects of body work that are often neglected in furtherance of discussion of power and resistance (Thrift, 2000; Radley, 1995), but which are made possible through the social character of the salsa form. This calls to mind Maffesoli's (2007) concept of the tribal aesthetic in relation to 'people feeling emotions together' (Maffesoli, 2007, p. 27). The tribal aesthetic, he argues, speaks of an ecological dialectic versus that of simply economic means-ends activities - a spirit which captures the sense of aesthetics as a 'passion for life' (ibid, 27) - a passion neatly communicated through the language of salsa. This also reiterates the pivotal role that such embodied aesthetic experiences perform in the formation of aesthetic subjectivities and identities (Venkatesh and Meamber, 2008; Joy and Venkatesh, 1994).

Rational systems of thought then pervade our working days; the language of calculation and rationality: talk of inflation and deflation, profit and loss, credit and crunch surrounds us in contemporary consumer culture. It is perhaps no surprise then that the night dances to a different tune where investments in expressive embodied forms and emotional connections reside. 2009 will probably go down as the year of the dance movie as sometimes it is best, as they say, to simply 'Shut up and dance' (McRobbie, 1993); but after the dancing, it is time to reflect and share those moments. That's what we think salseros are up to through their linking with impassioned others, as perhaps they know deep down, without the requirement for us to reveal, that as the ad intones Life's for Sharing since identities remain now more than ever, as the poet extols, an 'uncertain business' ${ }^{6}$

\section{Biographical notes}

Dr Paul Hewer (Strathclyde University, Glasgow) is interested in all things relating to culture and consumption. The majority of his research focuses upon theorizing and unpacking contemporary consumer culture, from culinary culture to dance tribes and car cultures. His work can be found in the following outlets, Journal of Marketing Management, Advances in Consumer Research amongst others.

Dr Kathy Hamilton is a lecturer in marketing at the University of Strathclyde, Glasgow. Kathy's research interests focus on understanding consumer culture. Key projects have related to consumer disadvantage, family consumption and gender issues, tribal consumption in dance and the consumption of celebrity. Kathy's research has been published in journals such as European Journal of Marketing, Journal of Consumer Bebaviour and Journal of Marketing Management.

${ }^{6}$ Seamus Heaney (1980), Preoccupations: Selected Prose 1968-1978. Faber \& Faber: London. 


\section{References}

Augé M. 195. Non-places: Introduction to an antbropology of super-modernity. Verso: London.

Belk RW, Costa JA. 1998. The mountain man myth: a contemporary consuming fantasy. Journal of Consumer Research 25: 218-240.

Bourdieu P. 1992. (orig. 1984). Distinction: A Social Critique of the Judgement of Taste. Routledge: London.

Brown S. 1998. Postmodern Marketing 2: Telling Tales. Thompson: London.

Butler J. 1993. Bodies That Matter: On the Discursive Limits of 'Sex'. Routledge: London.

Campbell C. 1987. The Romantic Ethic and the Spirit of Modern Consumerism. Basil Blackwell: Oxford.

Cohen S, Taylor L. 1992. Escape Attempts: The Theory and Practice of Resistance to Everyday Life, 2nd edn. Routledge: London.

Cova B, Cova V. 2002. Tribal marketing: the tribalisation of society and its impact on the conduct of marketing. European Journal of Marketing 36(5/6): 595-620.

Cushman P. 1990. Why the self is empty: towards a historically situated psychology. American Psychologist 45 599-611.

De Certeau M. 1984. The Practice of Everyday Life. University of California Press: London.

Dyer R. 1979. In defense of disco. Gay Left 8 20-23. Download a copy from: http://www.gayleft1970s.org/issues/gay.left_issue.08.pdf

Fraleigh SH. 1995. Dance and the Lived Body: A Descriptive Aesthetics. University of Pittsburgh Press: Pittsburgh.

Frank AW. 1991. For a sociology of the body: an analytical review. In The Body: Social Process and Cultural Theory, Mike F, Mike H, Bryan S (eds). Sage: London; 36-102.

Geertz C. 1974. The Interpretation of Cultures. Basic Books: New York.

Gitlin T. 2002. Media Unlimited: How the Torrent of Images and Sounds Overwhelms our Lives. Henry Holt \& Co.: New York.

Goffman E. 1972. Relations in Public. Harper \& Row: London.

Goulding C, Shankar A, Elliott R. 2002. Working weeks, rave weekends: identity fragmentation and the emergence of new communities. Consumption, Markets and Culture 5(4): 261-284.
Goulding C, Shankar A, Elliott R, Canniford R. 2008. The marketplace management of illicit pleasures. Journal of Consumer Research 35(5): 759771.

Hanna JL. 1988. Dance, Sex, and Gender. University of Chicago Press: Chicago.

Hamilton K, Hewer P. 2009. Salsa Magic: An Exploratory Netnographic Analysis of the Salsa Experience. In Advances in Consumer Research, Vol. 36, McGill AL, Shavitt S (eds). Association for Consumer Research: Duluth, MN; 502-508.

Hebdige D. 1979. Subculture: The Meaning of Style. Routledge: London.

Heaney S. 1980. Preoccupations: Selected Prose 1968-1978. Faber and Faber: London.

Joy A, Venkatesh A. 1994. Postmodernism, feminism, and the body: the visible and the invisible in consumer research. International Journal of Research in Marketing 11(4): 333-357.

Kozinets RV. 1998. On netnography: initial reflections on consumer research investigations of cyberculture. Advances in Consumer Research 25: 366-371.

Kozinets RV. 2001. Utopian enterprise: articulating the meanings of star trek's culture of consumption. Journal of Consumer Research 28: 67-88.

Kozinets RV. 1997. I want to believe: a netnography of the x-philes subculture of consumption. Advances in Consumer Research 24: 470-475.

Kozinets RV. 2002. Can consumers escape the market? Emancipatory illuminations from burning man. Journal of Consumer Research 29: 2038.

Luker K. 2008. Salsa Dancing into Social Science. Harvard University Press: Cambridge, MA.

Maffesoli M. 2007. Tribal aesthetic. In Consumer Tribes, Cova B, Kozinets RV, Shankar A (eds). Butterworth-Heinemann: Oxford; 27-34.

Maffesoli M. 1996. The Time of the Tribes: The Decline of Individualism in Mass Society. Sage: London.

McRobbie A. 1984. Dance and social fantasy. In Gender and Generation, Angela M, Mica N (eds). Macmillan: Basingstoke; 130-161.

McRobbie A. 1993. Shut up and dance: youth culture and changing modes of femininity. Young 1(2): 13-31.

Mestrovic SG. 1997. Postemotional Society. Sage: London. 
Radley A. 1995. The elusory body and social constructionist theory. Body \& Society 1(3): 3-23.

Ritzer G. 1993. The McDonaldization of Society: An Investigation into the Changing Character of Contemporary Social Life. Pine Forge: Los Angeles.

Saren M. 2007. Marketing is everything: the view from the street. Marketing Intelligence and Planning 25(1): 11-16.

Sherry JF, Schouten JW. 2002. A role for poetry in consumer research. Journal of Consumer Research 29: 218-234.

Stern BB. 1998. Narratological analysis of consumer voices in postmodern research accounts. In Representing Consumers, Barbara S (ed.). Routledge: London; 55-82.

Thomas H. 2003. The Body, Dance and Cultural Theory. Palgrave: London.

Thrift N. 2000. The Still Point: Resistance, Expressive Embodiment and Dance. In Geographies of Resistance, Steve P, Michael K (eds). Routledge: London; 124-151.

Turner V. 1982. From Ritual to Theatre: The Human Seriousness of Play. PAJ: New York.

Venkatesh A, Meamber LA. 2008. The aesthetics of consumption and the consumer as an aesthetic object. Consumption, Markets and Culture 11(1): 45-70.

Weber M. 1968. Economy \& Society: An Outline of Interpretive Sociology, Guenther R, Claus W (eds). Bedminster Press: New York.

Wilkinson IF, Young LC. 1994. Business dancing: an alternative paradigm for relationship marketing. Asia-Australia Marketing Journal 2(1): 6780 .
Willis P. 2000. The Ethnographic Imagination. Polity Press: Cambridge.

Wolff J. 1995. Resident Alien: Feminist Cultural Criticism. Yale University Press: London.

Woolf V. 1993. The Crowded Dance of Modern Life: Selected Essays: Vol. 2. Penguin: London.

Wort F, Pettigrew S. 2003. Consuming the belly dance. In European Advances in Consumer Research, Darach T, Stephen B (eds). Association for Consumer Research: Provo, UT; 187-192.

Zaner RM. 2002. Making music together while growing older: further reflections on intersubjectivity. Human Studies 25(1): 1-18.

A sampling of some of the Newspaper Articles on Salsa

Africa News. 2006. Strictly Salsa 2006 (First National Salsa Championship), Africa News, 22 December 2006.

Miami New Times. 2000. Salsa and Be Counted, Miami New Times, 25 May 2000.

Newcastle Evening Chronicle. 1998. Salsa night is all a bit of a wiggle, Newcastle Evening Chronicle, 22 July 1998.

New York Times. 2007. Salsa Spins Beyond Its Roots, New York Times, 29 July 2007.

Sunday Mirror. 1999. Salsa: The Sexiest Hobby Ever? Sunday Mirror, 3 January 1999.

The Singapore Straits Times. 2004. Salsa Seduction, The Straits Times, 10 October 2004.

Vancouver Sun. 2005. Salsa! For many, salsa, a sensual fusion of Afro-Cuban-Latino street music with early American jazz, isn't just a dance, it's a way of life, Vancouver Sun, 3 October 2005. 